\title{
Market equilibrium with price-beating firms under imperfect knowledge
}

Pedro Cosme Costa Vieira (pcosme@fep.up.pt); Faculdade de Economia do Porto 2009

\begin{abstract}
It is unquestionable both theoretically and empirically that trade in competitive markets is the best way to promote the efficient allocation of goods. Nevertheless, there could be some traders' strategies that interfere with competition, collusion among traders, which results in losses to society.

In this work, I study the implication that guarantees have on the competitiveness of the market when information is imperfect and costly. In formal terms, I study the 'price matching' and 'price beating' guarantees that may be extended to other types of guarantee.

From the theoretical model it results that both strategies are anti-competitive strategy but, contrary to 'price matching', 'price beating' is not in the best interest of sellers (in a Nash equilibrium perspective).
\end{abstract}

JEL codes: D82, D83, L12

Keywords: Collusion; Price beating guarantees; Imperfect information

\section{Introduction}

Guarantees are declarations from seller that its products have a certain quality standard. So, guarantees only make sense if they are a commitment on a characteristic that buyers do not known perfectly and if there is a compensation in case the claim is not accurate. Otherwise, it is "cheap talk" (e.g., Farrell, 1987).

The imperfect knowledge results from the existence of a search cost (e.g. the quantification of the effort to acquire the information) or resulting from the value to be realized in future (Lippman and McCall, 1981). 
Firm's guarantees may be in absolute or relative terms. The most common in absolute terms is the "good functioning" which encompass a legal obligation imposed on sellers that artifacts will be "good functioning" for at least a certain period of time. Other common guarantee is the "return if not pleased" by which a seller sustains that a buyer will not regret from the purchase.

Guarantees in relative terms are based on a comparison between goods, e.g., a cleaning product seller assuring that "this product cleans better that others".

The question I discuss in this work is whether guaranteeing is a strategy that increases competition between traders, which conduces to better products with smaller prices or, on the contrary, it turns possible sellers to collude, behaving as if they were monopolists, decreasing quality and increasing prices.

In this work I present a market equilibrium model with sellers guaranteeing in relative terms that their prices are no higher than other firms' prices. Then, I investigate whether it is, a priori, optimal sellers to promise paying the price difference or adding to that a compensation sum in case that the buyer discovers the claim is false.

Contrary to Corts (1995), I assume that buyers do not have perfect knowledge of prices.

\section{First strategy: firms matching other firms' prices}

There are $N$ identical firms that have constant and null marginal cost.

A firm sets the price and guarantees that it matches other firms' prices.

Firms do not know prices affixed by other firms.

There are $Q$ buyers, being $\alpha$ the fraction of uninformed buyers (that only known the price of one seller) and being $(1-\alpha)$ the fraction of informed buyers (that known the price of two sellers).

The assumption that there are a percentage of buyers that know the price of only a seller, tourists, is used, among others, in Salop and Stiglitz (1977), Wilde and Schwartz (1979) and Burdett and Judd (1983). If all buyers are identical, it is known from the literature that informed buyers only have to know the prices set by two firms (Burdett and Judd, 1983, p. 962, cl. 1). 
Since Simon (1955), imperfect knowledge is modeled assuming that the value is an extraction from a known aleatory function. In this vein, each firm assumes that other firms' strategy is to randomly pick a price from the distribution function $F(p)$.

\section{Property 1: If firms guarantee price matching, the equilibrium market} price will be unique and equal to the monopoly price

Proof: If a seller guarantee that matches other firms' price, all buyers that ask him the price, will buy. That result, on average, the quantity $Q / N$. In this way, a firm that affix price $P$ have the expected profit formalized by next expression:

$$
\begin{aligned}
E \mathbf{f}(P)^{-} & =\frac{Q}{N} P-\frac{Q}{N}(1-\alpha)\left(P-\int_{0}^{P} x f(x) d x\right) \\
& =\frac{Q}{N}\left(\alpha P+(1-\alpha) \int_{0}^{P} x f(x) d x\right)
\end{aligned}
$$

In a Nash equilibrium situation, the $F(x)$ function will be such that the expected profit function is horizontal (expected profit is identical to all prices observed in the market). In particular, considering there is a maximum price, Pmax, and a minimum price, $P \min$, for both extreme prices, it will result the same expected profit:

$$
\begin{aligned}
& E \mathbf{f}(P \min )_{-}^{-}=E \mathbf{t}(P \max )_{-}^{-} \\
& \alpha P \min +(1-\alpha) \int_{P_{\min }}^{P_{\min }} x f(x) d x=\alpha P \max +(1-\alpha) \int_{P_{\min }}^{P \max } x f(x) d x
\end{aligned}
$$

The average price is in-between Pmin and Pmax. Being so, one may assume $k \in$ $[0,1]$ and rewriting this expression results that Pmin must be equal to Pmax:

$$
\begin{aligned}
& P \min =\alpha P \max +(1-\alpha) \int_{P \min }^{P \max } x f(x) d x \\
& P \min =\alpha P \max +(1-\alpha)(P \max +(1-k) P \min - \\
& P \min =P \max , \forall \alpha, k
\end{aligned}
$$

Assuming that all firms set price $P$, except one firm that sets $p$, if $p$ is smaller than $P$, that firm's expected profit is $E \mathbf{t}(p)_{-}^{-}=Q / N p$. If $p$ is higher than $P$, that firm's 
expected profit is $E \mathbf{t}(p)_{-}^{-}=Q / N \ll p+(1-\alpha) P_{-}^{-}$. Thus, the firm's profit is increasing with the price affixed so the firm will affix the monopoly price (since there is at least one uninformed buyer). By symmetry, all firms set the monopoly price.

Assuming as Burdett and Judd (1983) that buyers have a positive search cost, the introduction of firms' price-matching cause the disappearing of equilibrium points with search and price dispersion so the unique equilibrium consists in sellers behaving as if they where monopolists.

QED

This result is identical to that of Salop (1986) and Corts (1995) who assume perfect knowledge.

\section{Second strategy: firms beat other firms' prices}

Now I investigate, in a market equilibrium situation, if it is optimal a firm to promise a priori to pay the price difference plus a compensation sum to everyone that finds a price lower than the seller guarantees and if that increases competition.

\section{Claim 1: Price beat with compensation is an anti competitive strategy.}

Proof: All buyers that search a firm buy there at price $P$. But a fraction $(1-\alpha)$ of them will ask the price to another seller and if they find a smaller price, they recover the price difference plus a percentage compensation $(1-\delta), 1 \geq \delta \geq 0$. Being so, the expected profit of that firm when it affixes price $P$ is:

$$
E \mathbf{F}(P)_{-}^{-}=\frac{Q}{N}\left(\alpha P+(1-\alpha)\left(\delta \int_{P \min }^{P} x f(x) d x\right)\right)
$$

In equilibrium, the expected profit function is horizontal. Therefore, from the minimum price, Pmin, and maximum price, Pmax, it must result the same expected profit:

$$
\alpha P \min +(1-\alpha) \int_{P \min }^{P \min } x f(x) d x=\alpha P \max +(1-\alpha)\left(\delta \int_{P \text { min }}^{P \text { max }} x f(x) d x\right)
$$

As explained, the average price is in-between $P \min$ and $P \max (0<k<1)$ 


$$
\begin{aligned}
& P \min =\alpha P \max +(1-\alpha) \delta\left(P \max +(1-k) P \min _{-}^{-}\right. \\
& P \max =P \min \frac{1-(1-\alpha)(1-k) \delta}{\alpha+(1-\alpha) \delta k}
\end{aligned}
$$

Comparing this value with the standard model of Wilde and Schwartz (1979), where $P \max =P \min (2-\alpha) / \alpha$, the price beating strategy decreases competition because $\frac{1-(1-\alpha)(1-k) \delta}{\alpha+(1-\alpha) \delta k}<\frac{2-\alpha}{\alpha}$.

Nevertheless, price-beating guarantees increase the competitiveness in relation to the price-matching strategy because the difference between maximum price and minimum price observed in the market is increasing with compensation, $1-\delta$.

Property 2: In market equilibrium, price beating strategy is dominated by price matching strategy, so no firm will adopt such strategy.

Proof: It is known that if $\delta=1$, there is no price dispersion so the market average price is equal to the maximum price (Property 1 ). If $\delta<1$, whatever is the price dispersion distribution, $F(x)$, the market average price, $\int_{P_{\min }}^{P_{\max }} x f(x) d x$, is not higher than the maximum price. Then, if a seller affixes the maximum price, his expected profit that results from expression (4) is increasing with $\delta$ :

$$
\frac{d E \mathbf{\gamma}(P \max )^{-}}{d \delta}=\frac{Q}{N}\left((1-\alpha) \bar{P} \frac{d \bar{P}}{d \delta}\right)
$$

Being so, in a situation of market equilibrium, sellers do not have incentives to price beat but only to price matching $(\delta=1)$ other sellers, situation already studied above. 
Note that Corts (1995)'s result that price beating guarantee is pro-competitive and that push the market to the perfect competition situation $(P \max =P \min =0)$ is a particular result of my model for $\alpha=0$.

\section{Conclusion}

I derive theoretically that, under imperfect knowledge, price-beating strategy is anti competitive. Nevertheless, this strategy is not in the interest of sellers because it is dominated by price matching strategy. This theoretical result is in conflict with Corts (1995)'s but it is in accordance with the very low occurrence of such phenomena in real world.

The price matching strategy is a limit situation of the price beating strategy and it is an anti-competitive strategy, resulting that sellers behave as if they where monopolist. Therefor, the price matching strategy interferes with competition promoting collusion among traders, which results in losses to society.

\section{Bibliographic References}

Burdett, Kenneth, e Kenneth L. Judd (1983), "Equilibrium Price Dispersion", Econometrica, vol. 51, pp. 955-69.

Corts, Kenneth S. (1995), "On the Robustness of the Argument that Price Matching is Anti-competitive”, Economic Letters, vol. 47, pp. 417-421.

Farrell, Joseph (1987),“Cheap Talk, Coordination, and Entry”, Rand Journal of Economics, vol. 18, pp. 34-9.

Lippman, Steven A., e John J. McCall (1981), "The Economics of Belated Information", International Economics Review, vol. 22(1), pp. 135-54.

Salop, Steven (1986) "Practices that (credibly) facilitate oligopoly coordination", in George Stigler and Frank Mathewson, eds, New Developments in the Analysis of Market Structure, MIT Press, Cambridge. MA 
Salop, Steven, e Joseph E. Stiglitz (1977), "Bargains and Ripoffs: A Model of Monopolistically Competitive Price Dispersion", Review of Economic Studies, vol. 44, pp. 193-510.

Simon, Herbert A. (1955), “A Behavioural Model of Rational Choice”, The Quarterly Journal of Economics, vol. 64, pp. 99-118.

Stigler, George (1964), A Theory of Oligopoly, Journal of Political Economy, vol. 72, pp.44-61.

Wilde, Louis L. and Alan Schwartz (1979), "Equilibrium Comparison Shopping", Review of Economic Studies, vol. 46, pp. 543-54. 